\title{
Epidemiology of typhoid fever in Singapore
}

\author{
F. S. YEW ${ }^{1}$, K. T. GOH ${ }^{1}$ AND Y. S. LIM ${ }^{2}$ \\ ${ }^{1}$ Quarantine and Epidemiology Department, Ministry of the Environment, \\ Singapore, 40 Scotts Road, Singapore 0922 \\ ${ }^{2}$ Enteric Bacteriology Laboratory, Department of Pathology, Singapore General \\ Hospital, Singapore
}

(Accepted 10 September 1992)

SCMMARY

A total of 1452 cases of typhoid fever was notified in Singapore from 1980-9. The morbidity rates of indigenous cases showed a steady decline from 5.9 per 100000 population in 1980 to 1.2 per 100000 population in 1989 . The mean case fatality was $0 \cdot 8 \%$. Children, adolescents and young adults were most susceptible to typhoid fever. There was no significant difference in morbidity rates between the major ethnic groups. The vast majority of indigenous cases were sporadic while outbreaks accounted for almost one third of them. Food was the main vehicle of transmission. The commonest indigenous phage types were B1, D1 and A. Antimicrobial resistance was infrequently seen. The proportion of imported cases rose from $32 \%$ in 1980 to $72 \%$ in 1989 . Almost half $(48.5 \%)$ of all imported cases were local residents who contracted typhoid fever while travelling in endemic countries. As imported cases assume greater importance in the epidemiology of typhoid fever in Singapore, further drop in typhoid fever incidence would require reduction of travel-related cases through greater awareness of food hygiene and effective vaccination.

\section{INTRODCCTION}

Typhoid fever is strictly a human disease. It is mostly spread by consumption of food and water contaminated with Salmonella typhi and rarely by direct faecaloral route through poor sanitation and poor personal hygiene. The incidence of typhoid fever is closely associated with the availability of safe water supply, food and personal hygiene and environmental sanitation [1]. In developed countries like the United States [2,3] and Japan [4] where a safe water supply is readily available and standards of environmental sanitation and food hygiene are high, the incidence of typhoid fever is well below 1 per 100000 population. In these developed countries, travel-related cases of typhoid fever form a significant proportion of the cases reported $[3,5,6]$. In contrast, higher incidence rates ranging from 10 to above 100 per 100000 population have been reported in the less developed countries $[7,8]$ where the majority of cases tend to be locally acquired. Over the last three decades, the annual incidence of indigenous typhoid fever in Singapore has been declining steadily [9-11] from about 10 per 100000 population in the 1950's to stabilize at around 1 per 100000 population in the late 1980's [12]. Despite this decline, between 100 and 200 cases continue to be notified annually 
during the period 1980-9. We report a change in the epidemiology of typhoid fever in Singapore where imported cases are assuming greater importance.

\section{IIETHODS}

The notification of typhoid fever in Singapore is mandatory by law. Notifications are received from government and private hospital doctors, general practitioners as well as government and private medical laboratories. All notified cases were individually investigated by public health auxiliaries and information such as biodata, basic clinical history, laboratory investigations, food history and travel history were recorded in standard investigation forms. All close contacts and implicated food handlers were sent for routine stool culture screening on three consecutive days. Cases were classified as imported if there was a history of travel to an endemic country between 7 and 21 days before the onset of symptoms. Antimicrobial susceptibility tests and phage-typing were routinely carried out for all cases reported from government hospitals. Salmonella typhi strains were phagetyped by a standard method [13,14]. All $S$. typhi isolates were tested for their susceptibility to common antimicrobial agents using the disk diffusion method [15]. Patients who were local residents were scheduled for post-treatment followup at 3,6 and 12 months at the Communicable Disease Centre, during which stool and urine cultures were taken. Those who persisted in excreting S. typhi during convalescence were defined as convalescent carriers, those who persisted at $3-6$ months were defined as temporary carriers and those who persisted in excreting at 1 year or longer were defined as chronic carriers.

\section{RESLLTS}

A total of 1452 cases was notified during the period $1980-9$, with a median annual incidence of 156.5 cases (Table 1 ). There were 11 fatal cases, giving a mean case fatality rate was $0.8 \%$. Seven hundred and fifty-one cases $(51.7 \%)$ were classified as imported and $701(48 \cdot 3 \%)$ as indigenous. Antimicrobial susceptibility tests and phage-typing were done for $1277(87.9 \%)$ of the 1452 cases.

\section{Indigenous cases}

The morbidity rates of indigenous cases showed a steady decline over the 10 year period under study from 5.9 per 100000 population in 1980 to $1 \cdot 2$ per 100000 population in 1989 (Fig. 1). Children, adolescents and young adults appeared to be most susceptible to typhoid fever. Those in the 5-14 years age group had the highest morbidity rate followed closely by those in the 15-25 years age group (Fig. 2). Male and female morbidity rates were about equal. All the three major ethnic groups experienced a gradual decline in morbidity rates over the years. The mean morbidity rate of Malays ( $3 \cdot 3$ per 100000 population) was almost the same as that of Indians (2.9 per 100000 population) but $1 \cdot 7$ times that of Chinese (1.9 per 100000 population). There was little variation in the geographical and monthly distribution of indigenous cases.

Outbreaks accounted for almost one third of all the indigenous cases notified (an outbreak was defined as two or more cases believed to have originated from a common source). A total of 33 outbreaks involving 199 cases was reported during 
Table 1. Incidence of typhoid fever in Singapore, 1980-9

$\begin{array}{cccc}\text { Year } & \text { Local cases } & \text { Imported cases } & \begin{array}{c}\text { Total } \\ \text { (Deaths) }\end{array} \\ 1980 & 142 & 68 & 210(2) \\ 1981 & 133 & 56 & 189(2) \\ 1982 & 91 & 73 & 164(2) \\ 1983 & 54 & 72 & 126(1) \\ 1984 & 39 & 58 & 97 \\ 1985 & 65 & 58 & 123(2) \\ 1986 & 62 & 88 & 150(1) \\ 1987 & 37 & 77 & 114 \\ 1988 & 45 & 118 & 163 \\ 1989 & 33 & 83 & 116(1) \\ \text { Total } & 701 & 751 & 1452(1) \\ & & & \end{array}$

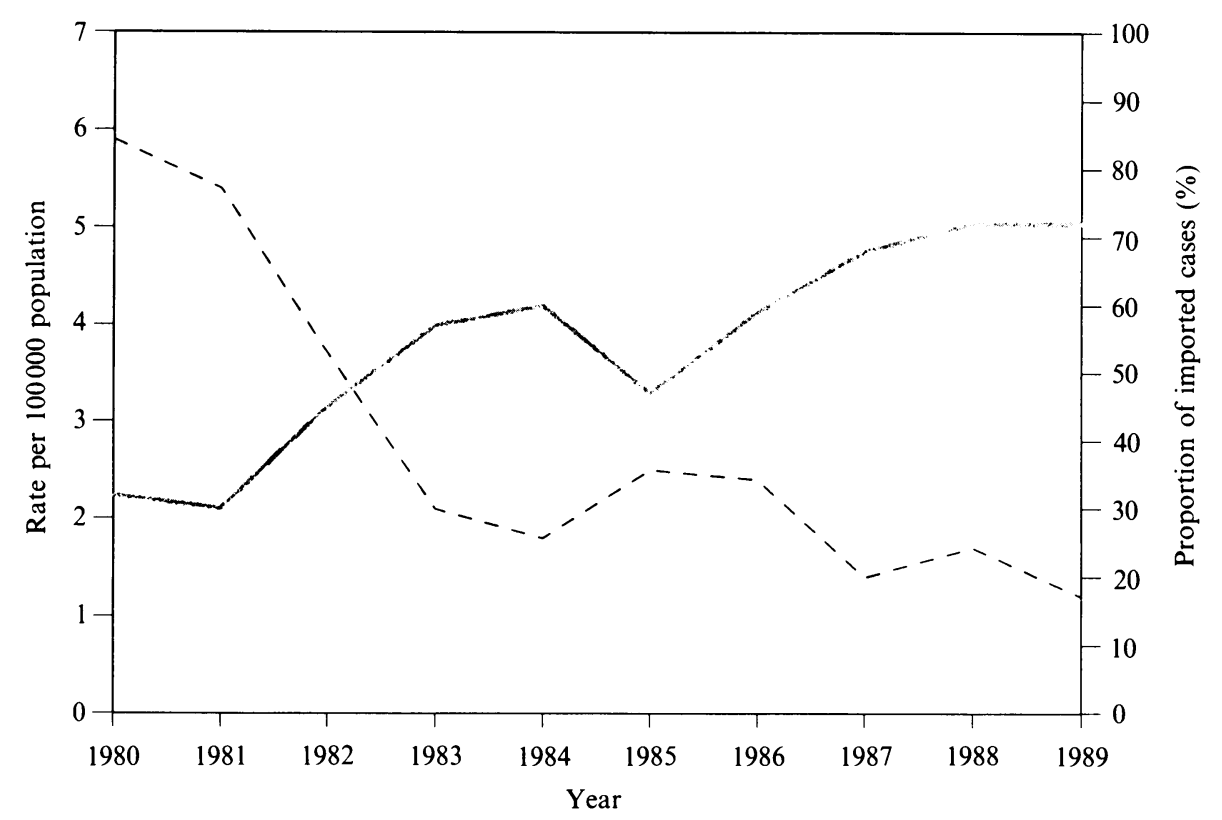

Fig. 1. Morbidity rates of indigenous typhoid fever and proportion of imported cases in Singapore, 1980-9. (---) rates per 100000 population, $(-)$ proportion of imported cases $(\%)$.

the 10-year period. Seven $(21 \cdot 1 \%)$ were large outbreaks involving 11-23 cases while $23(69 \cdot 6 \%)$ involved 3 to 9 cases and $3(9 \cdot 1 \%)$ involved only 2 cases. Eighteen outbreaks involved members of the same household. Public food handlers were implicated in 12 outbreaks. The source of transmission in 10 $(30 \cdot 3 \%)$ outbreaks was traced and confirmed by phage typing. Five of these were traced to carriers within the same household (including one foreign domestic maid), one to a carrier who was a food handler and four to carriers among inmates of two mental institutions. None of the carriers were in the national typhoid carrier register. Five other outbreaks were traced to household contacts of cases. Various foods such as iced drinks, cut fruits, salads and undercooked chicken had been implicated as vehicles of transmission during epidemiological investigations. 




Fig. 2. Mean annual age-specific morbidity rates of indigenous typhoid fever in Singapore, 1980-9.

\section{Imported cases}

Over the last decade, the proportion of imported cases has been steadily rising from $32 \%$ in 1980 to $72 \%$ in 1989 (Fig. 1). The vast majority of cases were imported from Indonesia $(52.4 \%)$ and India $(26 \cdot 6 \%)$. Smaller numbers were imported from Malaysia $(9 \cdot 7 \%)$ and Thailand $(4 \cdot 7 \%)$. Local residents who contracted the disease while travelling in endemic countries accounted for about half $(48.5 \%)$ of all imported cases while foreigners who came to Singapore for medical treatment comprised about a third $(29.9 \%)$. The remainder were tourists, work permit and student pass holders. While no great variation was noticed in the monthly distribution of indigenous cases, a distinct bimodal distribution with peaks in January and July was noted among imported cases (Fig. 3).

\section{Carriers}

From 1980 through 1989, a total of 42 male and 29 female carriers were notified. They comprised 2 chronic carriers, 47 temporary carriers and 22 convalescent carriers. A substantial proportion $(70.4 \%)$ of the carriers were below 45 years of age when detected. Ten $(14 \cdot 1 \%)$ carriers were food handlers. The vast majority were stool carriers identified through follow-up screening of previously treated cases as well as screening of close contacts and implicated food handlers. There were no urinary carriers. Six carriers were detected incidentally when samples of bile taken after cholecystectomy grew S. typhi.

\section{Phage types and drug resistance}

The three commonest phage types among indigenous cases were B1 (17.6\%), D1 $(13 \cdot 3 \%)$ and $A(12 \cdot 2 \%)$. Among imported cases, the commonest phage types isolated and countries of origin were UVS1, D2 and UVS2 from Indonesia, A, E1 and UVS1 from India and B1, D1 and E1 from Malaysia. During the 10-year period, only 8 chloramphenicol-resistant strains of $S$. typhi (7 imported and 1 indigenous) were isolated (Table 2). Less than $1 \%$ of the strains were resistant to either chloramphenicol, ampicillin or co-trimoxazole. A total of seven strains was 


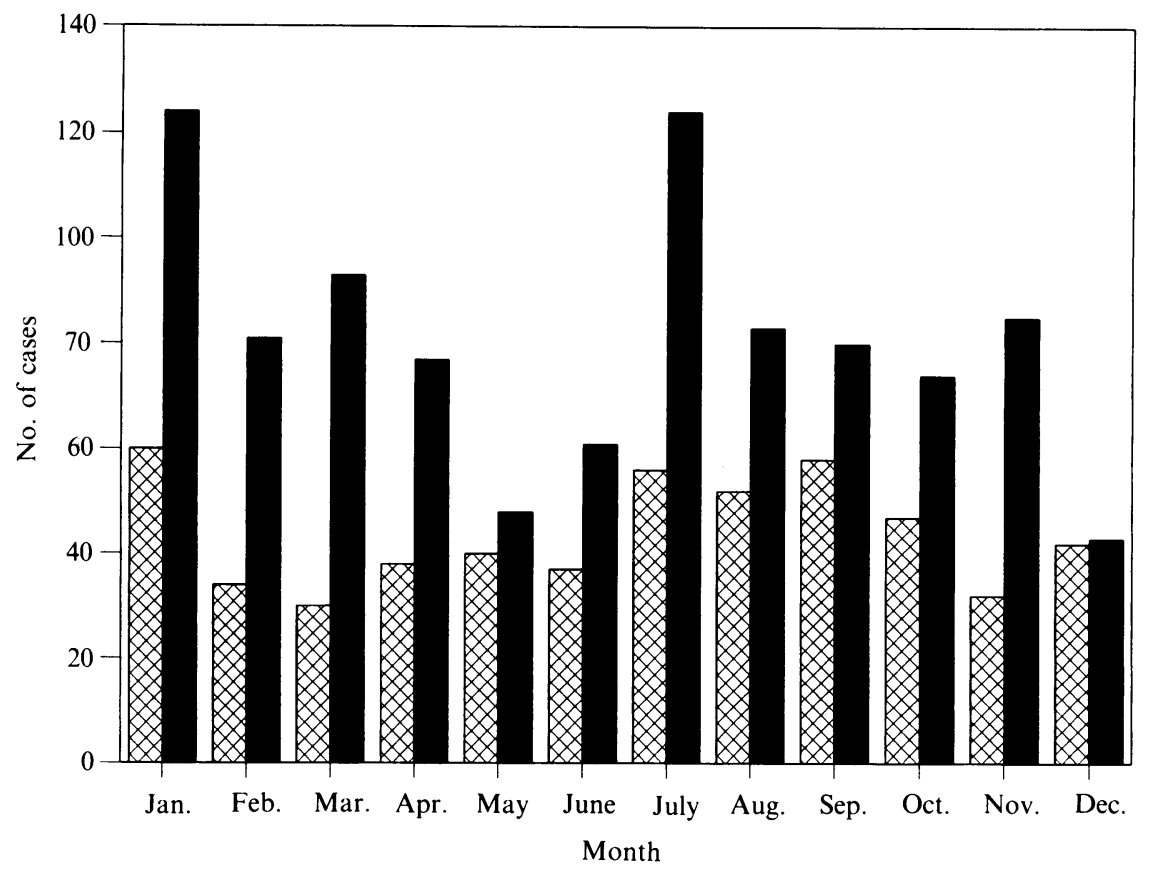

Fig. 3. Monthly distribution of indigenous and imported typhoid fever cases in Singapore, 1980-9. $\otimes$, indigenous cases. $\square$, imported cases.

Table 2. Antimicrobial resistance of 1277 S. typhi strains in Singapore, 1980-9

\section{Antimicrobial drug}

Ampicillin

Chloramphenicol

Co-trimoxazole

Gentamicin

Kanamycin

Sulphonamides

Tetracycline

Multi-resistant pattern*

ACSxtSuT

CSuT

CSu
Number of resistant strains (\%)

$$
\begin{gathered}
4(0 \cdot 3) \\
8(0 \cdot 6) \\
4(0 \cdot 4) \\
0 \\
0 \\
302(23 \cdot 6) \\
8(0 \cdot 6) \\
\\
4(0 \cdot 3) \\
2(0 \cdot 2) \\
1(0 \cdot 1)
\end{gathered}
$$

* A, ampicillin; C, chloramphenicol; Sxt, co-trimoxazole; Su, sulphonamides; T, tetracycline.

found to be multi-resistant. The first indigenous chloramphenicol-resistant strain was isolated in 1989. It was also resistant to ampicillin, co-trimoxazole, sulphonamides and tetracycline.

\section{DISCUSSION}

The steady decline in indigenous typhoid fever over the last decade was mainly due to improved standards of food hygiene through better control of public food handlers together with more extensive provision of modern sanitation and safe water supply. In Singapore, engaging in the food trade without a licence is not permitted. Food handlers who are known typhoid carriers are prohibited from handling food indefinitely. In addition, food handlers who have been treated for 
typhoid fever are also not allowed to engage in the food trade until they are cleared of the carrier state after at least 6 months of follow-up. As street hawkers, who have no easy access to potable water and modern sanitation, contribute to poor food hygiene and environmental pollution, large numbers of them were resited over the last two decades to markets and food centres where modern amenities were easily available. By 1989, only $174(0.8 \%)$ of 21097 hawkers operated outdoors compared with $13578(60 \%)$ out of 22574 hawkers in 1975 [16]. Furthermore, the proportion of the population provided with modern sanitation increased from $76 \%$ in 1975 and to almost $100 \%$ in 1989 [16]. All parts of Singapore were supplied with potable water by 1983 [17]. However, we note that even the lowest morbidity rate of indigenous typhoid fever recorded was still much higher than those of other developed countries such as the United States $(0 \cdot 2$ per 100000 population) [3] and Japan (0.1 per 100000 population) [4]. We believe the higher morbidity rates as largely due to an estimated $1500-2000$ chronic carriers [18] who had accumulated through the years and continued to cause some sporadic cases and localized outbreaks despite high standards of environmental control measures.

Food was the main vehicle of transmission in the last decade. Large outbreaks were infrequent and no water-borne outbreak was reported. No outbreak was traced to previously known carriers. Person-to-person transmission was insignificant but could have played a role in the four mental institution outbreaks. In such institutions where personal hygiene could not be ensured, additional control measures included close surveillance for early cases and their immediate isolation, carrier detection using sewerage-tracing surveillance $[19,20]$ and typhoid vaccination of inmates.

As S. typhi in carriers are known to be intermittently excreted in stools [21], our experience confirmed the low sensitivity of using multiple faecal cultures to trace the source of transmission in outbreaks. Only one carrier was identified in $\mathbf{1 2}$ outbreaks where food handlers were implicated. Combining multiple faecal cultures with some of the reportedly more sensitive methods such as bile sampling with a string capsule device [22] and various Vi antibody serological tests [23-28] could well improve the carrier detection rate.

The predominant phage types among indigenous isolates in the 1970's [29] were B1, D1 and A and continued to be so in the 1980's while the predominant phage types in the neighbouring countries of Malaysia were A, E1 and D1 [30] and Indonesia were I+ IV, D2 and A [31], with phage type A being common in all three countries. Since chloramphenicol resistance in S. typhi was reported in England in 1950 [32], it has spread eastwards to Greece, Israel, Africa and India in the 1960's [33-37] and to Vietnam, Thailand, Indonesia and Malaysia in the 1970's [38-41]. It did not emerge in Singapore until more than 10 years later in 1989 . We believe the delay was because of prudent and stringent control of chloramphenicol use on the island. Chloramphenicol remains the drug of choice in the treatment of typhoid fever in Singapore [42]. Resistance to ampicillin and co-trimozaxole was also relatively rare with less than $1 \%$ of strains being resistant compared to a resistance of $3 \%$ to ampicillin, $7 \%$ to co-trimoxazole and $4 \%$ to chloramphenicol in the United States [3].

Imported cases formed a large proportion of all typhoid fever cases seen in Singapore and showed a rising trend over the last decade. More than half of all cases 
notified since 1986 were imported. While local residents who contracted typhoid fever during their travel in endemic countries comprised the largest proportion of all imported cases, a substantial $30 \%$ were foreigners who had come to Singapore for medical treatment. We also observe a distinct increase in the incidence of imported cases in January and July. These months coincided with the end of the school holidays in Singapore. This bimodal time distribution was most probably due to local residents who were infected while on vacation in endemic countries.

As the incidence of indigenous cases is expected to decline further with time due to high standards of food and environmental hygiene and natural attrition of chronic carriers, imported cases will assume greater importance. Greater awareness on food hygiene and typhoid vaccination among local travellers would be needed to achieve a further drop in the incidence of typhoid fever. However, although the traditional inactivated vaccines confer reasonable protection, they are associated with frequent systemic and local adverse reactions $[43,44]$ and may not be popular with travellers. Wider use of more efficient vaccines which have less adverse effects like the single dose Vi capsular polysaccharide vaccine $[45,46]$ or the oral Ty21a vaccine $[47,48]$ would be a step towards the reduction in travel-related typhoid fever.

\section{REFERENCES}

1. Cvjetanovic B. Typhoid fever and its prevention. Pub Hlth Rev 1973; 2 : 230-43.

2. Rice PA, Baine WB, Gangarose EJ. Salmonella typhi infections in the United States, 1967-1972: increasing importance of international travellers. Am J Epidemiol 1977; 106 : $160-6$.

3. Ryan CA, Hargrett BNT, Blake PA. Salmonella typhi infections in the United States, 1975-1984 : increasing role of foreign travel. Rev Infect Dis 1989; 11 : 1-8.

4. Seamic. Seamic Health Statistics 1986. International Medical Foundation of Japan 1987 : 48.

5. Sharp JCM, Heymann CS. Enteric fever in Scotland, 1967-1974. J Hyg 1976; 76 : 83-9.

6. Public Health Laboratory Service Standing Sub-Committee on Bacteriological Examination of Water Supplies. Waterborne infectious disease in Britain. J Hyg 1978; 81: $139-49$.

7. Levine MM, Black RE, Lanata C, Chilean Typhoid Committee. Precise estimation of the numbers of chronic carriers of Salmonella typhi in Santiago, Chile, an endemic area. J Infect Dis $1982 ; 146$ : 724-6.

8. Somerville PC, Notelovitz J, Alberts M. Typhoid fever in the Northern Transvaal national states. An approach to an epidemiological quandry. S Afr Med J 1981; 60 : 491-5.

9. Ng SY, Leong KW. Typhoid fever in Singapore. Proceedings of the Alumni Association, Malaya $1955 ; 8$ : $183-9$.

10. Koh TS, Goh KT. Enteric fever surveillance in Singapore. Sing Med J 1976; 17 : 32-7.

11. Goh KT. Enteric infections in Singapore with special reference to typhoid. Southeast Asian J Trop Med Pub Hlth 1978; 9: 433-8.

12. Committee on Epidemic Diseases. Epidemiology of typhoid fever in Singapore 1980-1989. Epidemiol News Bull 1990; 16 : 3-5.

13. Cragie J, Felix A. Typing of typhoid bacilli with Vi bacteriophage. Lancet $1947 ; \mathbf{i}$ : $823-7$.

14. Anderson ES, Williams REO. Bacteriophage typing of enteric pathogens and staphylococci and its use in epidemiology. J Clin Pathol 1956; 9: 94-127.

15. Bauer AW, Kirby WMM, Sherris JC, Turck M. Antibiotic susceptibility testing by a standardized single disk method. Am J Clin Pathol 1966; 45 : 493-6.

16. Singapore, Ministry of the Environment. Annual report of Ministry of the Environment, 1976-1990.

17. Singapore, Ministry of Culture. Singapore, 1984.

18. Cvjetanovic B. Control of enteric fever. Sing Med J 1976; 17 : 38-9.

19. Moore B, Perry EL, Chard ST. A survey by the sewage swab method of latent enteric infection in an urban area. J Hyg $1952 ; 50$ : 137-56. 
20. Shinohara N, Tanaka H, Saito T, et al. Detection of carriers of typhoid bacilli by seweragetracing surveillance in Matsuyama City. Jpn J Med Sci Biol 1981; 34 : 385-92.

21. Christie AB. Typhoid and paratyphoid fevers. In: Christie AB, ed. Infectious diseases: epidemiology and clinical practice, 3rd edn. Edinburgh: Churchill Livingston, 1980: $47-102$.

22. Gilman RH, Islam $\mathrm{S}$, Rabbani H, Ghosh H. Identification of gallbladder typhoid carriers by a string device. Lancet $1979 ; \mathbf{i}: 795-6$.

23. Nolan CM, White Jr PC. Vi serology in the detection of typhoid carriers. Lancet 1981 ; : 583-4.

24. Chau PY, Tsang RSW. Vi serology in screening of typhoid carriers: improved specificity by detection of $\mathrm{Vi}$ antibodies by counterimmunophoresis. J Hyg 1982; 89: 261-7.

25. Engleberg NC, Barrett TJ, Fisher H, et al. Identification of a carrier by using Vi enzymelinked immunosorbent assay serology in an outbreak of typhoid fever on an Indian reservation. J Clin Microbiol 1983; 18: 1320-2.

26. Lanata CF, Ristori C, Jimenez L, et al. Vi serology in detection of chronic Salmonella typhi carriers in an endemic area. Lancet $1983 ;$ ii : $441-3$.

27. Losonsky GA, Ferreccio C, Kotloff KL, Kaintuck S, Robbins JB, Levine MM. Development and evaluation of an enzyme-linked immunosorbent assay for serum $\mathrm{Vi}$ antibodies for detection of chronic Salmonella typhi carriers. J Clin Microbiol 1987; 25 : 2266-8.

28. Lin FYC, Becke JM, Groves C, et al. Restaurant-associated outbreak of typhoid fever in Maryland: identification of carrier facilitated by measurement of serum Vi antibodies. J Clin Microbiol 1988; 26 : 1194-6.

29. Lam S, Goh KT. Vi phage types in Singapore. Sing Med J 1978; 19: 3-8.

30. Jegathesan M. Phage types of Salmonella typhi in Malaysia over the 10-year period 1970 1979. J Hyg 1983; $90: 91-7$.

31. Sanborn WR, Vieu JF, Komalarini S, et al. Salmonellosis in Indonesia: phage type distribution of Salmonella typhi. J Hyg 1979; 82: 143-53.

32. Colquhoun J, Weetch RS. Resistance to chloramphenicol developing during treatment of typhoid fever. Lancet 1950 ; ii : 621 .

33. Kontomichalou P. Studies on resistance transfer factors. Pathol Microbiol $1967 ; 30: 71-93$.

34. Sompolinsky D, Ben-Yakov M, Aboud M, Bolbur I. Transferable resistance factors with mutator effect in Salmonella typhi. Mutat Res 1967; 4: 119-27.

35. Njoku-Obi AN, Njoke-Obi JC. Resistance of Salmonella typhosa to chloramphenicol. $J$ Bacteriol $1965 ; 90$ : 552-3.

36. Murti B, Rajyalakshmi K, Bhaskaran CS. Resistance of Salmonella typhi to chloramphenicol. J Clin Pathol 1962; 15 : 544-51.

37. Paniker CKJ, Vimala KN. Transferable chloramphenicol resistance in Salmonella typhi. Nature 1972; 239: 109-10.

38. Brown JD, Mo DH, Rhoades ER. Chloramphenicol-resistant Salmonella typhi in Saigon. JAMA $1975 ; 231$ : $162-6$.

39. Lampe RM, Mansuwan P, Duangmani C. Chloramphenicol-resistant typhoid. Lancet 1974; i : $623-4$.

40. Sanborn WR, Lesmana M, Dennis DT, et al. Antibiotic-resistant typhoid in Indonesia. Lancet 1975 ; ii : $408-9$.

41. Jegathesan M, Khor SY. First isolates of chloramphenicol resistant S. typhi in Malaysia. Malaysia Med J 1980; $34: 395-7$.

42. Yew FS, Chew SK, Goh KT, Monteiro EHA. Typhoid fever in Singapore: a review of 370 cases. J Trop Med Hyg 1991 ; 94 : 352-7.

43. Center for Disease Control. Typhoid immunization: Recommendations of the Immunization Practices Advisory Committee (ACIP). MMWR 1990; 39 (RR-10) : 1-5.

44. Levine MM. Modern vaccines: enteric infections. Lancet $1990 ; 335$ : 958-61.

45. Acharya IL, Lowe CU, Thapa R, et al. Prevention of typhoid fever in Nepal with the Vi capsular polysaccharide of Salmonella typhi. N Eng J Med 1987; 317: 1101-4.

46. Klugman KP, Gilbertson IT, Koornhof HJ, et al. Protective activity of Vi capsular polysaccharide vaccine against typhoid fever. Lancet $1987 ; \mathbf{i}: 1165-9$.

47. Wahdan MH, Serie C, Cerisier Y, Sallam S, Germanier R. A controlled field trial of live Salmonella typhi strain Ty 21 a oral vaccine against typhoid: three-year results. J Infect Dis $1982 ; 145$ : $292-5$.

48. Levine MM, Ferreccio C, Black RE, et al. Large-scale field trial of Ty21a live oral typhoid vaccine in enteric-coated capsule formulation. Lancet $1987 ; \mathbf{i}: 1049-52$. 